\title{
Conservação pós-colheita de Sorvetão (Zingiber spectabile Griff.) utilizando filme plástico em diferentes pontos de colheita
}

\author{
ROBSON ASSUNÇÃO CAVALCANTE(1), JOSÉ LUIZ MOSCA(2), WALDELICE OLIVEIRA DE PAIVA(2), \\ VLAYRTON TOMÉ MACIEL ${ }^{(3)}$, JOÃO BATISTA SALMITO ALVES DEALMEIDA ${ }^{(4)}$, ADRIANAANDRADE GUIMARÃES(5)
}

\section{RESUMO}

Hastes florais de sorvetão (Zingiber spectabile Griff.) colhidas no Câmpus Experimental da Embrapa Agroindústria Tropical, situada em Fortaleza (CE),; em dois estádios de colheita: inflorescências com abertura completa e abertura incompleta na região apical, foram submetidas ao processo de limpeza e imersas em solução fúngica. Em seguida, procedeu-se ao corte basal das hastes (mantendo comprimento padrão de $40 \mathrm{~cm}$ ) e hidratação, realizada por um período de uma hora em recipientes contendo água. As hastes foram colhidas no estádio 1 (inflorescências com abertura completa na região apical) e no estádio 2 (inflorescências que apresentavam abertura incompleta na região apical), embaladas ou não em filme de PVC de $15 \mu \mathrm{m}$ de espessura. Em seguida, colocadas em caixas de papelão, tipo telescópio, usadas comercialmente (dimensões de 1,0 $\mathrm{m}$ de comprimento; $0,32 \mathrm{~m}$ de largura e $0,2 \mathrm{~m}$ de altura) e armazenadas em câmaras frias em temperatura de $15^{\circ} \mathrm{C}$ e $85 \%$ de UR. Diariamente foram avaliadas perda de massa, aparência visual, além da longevidade floral. O experimento foi conduzido em delineamento inteiramente casualizado em esquema fatorial $2 \times 2$, e o primeiro fator referiu-se aos dois pontos de colheita e o segundo,ao uso ou não do filme de PVC; com três repetições e cinco hastes por repetição. Não houve interação significativa entre os fatores pontos de colheita e uso ou não de filme de PVC para as variáveis estudadas. O revestimento das hastes florais com filme de PVC foi eficiente na redução da perda de massa para ambos os pontos de colheita. As maiores notas para aparência visual e maior longevidade floral foram atingidas em hastes florais colhidas no estádio 1 revestidas com filme de PVC. Não houve diferenças significativas entre os pontos de colheita para perda de massa e longevidade floral.

Palavras chave: flor tropical, pós-colheita, atmosfera modificada

\begin{abstract}
Post harvest conservation of beehive ginger (Zingiber spectabile Griff.) at two harvest stages wrapped in plastic film Floral stems of gingiber (Zingiber spectabile Griff.) harvested at the Experimental Campus of Embrapa Tropical Agroindustry, located in Fortaleza, State of Ceará; in two harvest stages: inflorescences complete and incomplete opening in the apical zone were submitted to the process of cleaning and immersed in fungicide solution. Afterwards it was proceeded the cut of the base of the stems (maintaining standard of $40 \mathrm{~cm}$ long), followed by hydration of a period of one hour in recipients containing taper water. The stems harvested at stage 1 (inflorescences with complete opening in the apical zone) and stage 2 (inflorescences that presented incomplete opening in the apical zone) were wrapped or not in stretch polyvinylchloride film (PVC) with $15 \mu \mathrm{m}$ of thickness After, they were placed in cardboard boxes, type telescope, used commercially (dimensions of 1,0 m of length; 0,32 $\mathrm{m}$ of width and $0,2 \mathrm{~m}$ of height) and stored in cold cameras in temperature of $15^{\circ} \mathrm{C}$ and $85 \%$ of RH. Daily it was evaluated the loss of fresh weight, visual appearance and floral longevity. The experiment was arranged in complete randomized design in a factorial outline $2 \times 2$, where the first factor referred to the two harvest stages and the second factor concerning to the use or not of the film of PVC; with three replicates and five stems per repetition. There was not significant interaction between stage of harvest and use or not of film of PVC for weight loss, visual appearence and floral longevity. The PVC was efficient in reducing the weight loss for the flowers in both stages of harvest. The highest grades for the visual appearance and lfloral longevity were reached for the stems harvest at stage 1 and wrapped with PVC film. There were not significant differences among the stages of harvest for the loss of fresh weight and floral longevity.
\end{abstract}

Key words: Tropical flower, post harvest, modified atmosphere

\section{INTRODUÇÃO}

O Brasil dispõe de imenso potencial para produção de flores e folhagens em decorrência da diversidade de clima, larga oferta de terra, disponibilidade de água entre outros fatores edafoclimáticos.

Para LOPES e GRAZIANO (2001), o mercado mundial tem-se mostrado saturado para plantas ornamentais tradicionalmente utilizadas, constituindo oportunidade de incremento na produção de espécies diferenciadas.

$\mathrm{O}$ interesse por produtos diferenciados, fato influenciado pela divulgação de novas espécies e variedades por meio da mídia e algumas empresas, faz com

\footnotetext{
(1) Universidade Federal do Ceará, bolsista CNPq; agrobson@gmail.com

(2) Embrapa Agroindústria Tropical - Rua Dra. Sara Mesquita, 2270 - Pici, 60511-110, Fortaleza( CE); mosca@cnpat.embrapa.br

(3) Embrapa Agroindústria Tropical, Eng. Agron., bolsista CNPq; vlayrton@gmail.com

(4) IICA/Embrapa Agroindústria Tropical, consultor; salmito10@gmail.com

(5) Doutoranda de Fitotecnia da Universidade Federal de Viçosa, adrianaguima@yahoo.com.br
} 
que algumas espécies se destaquem, entre elas estão as tropicais da ordem Zingiberales (LOPESEGRAZIANO, 2001).

Conhecida como gengibre ornamental, cotonete de elefante, sorvetão (Zingiber spectabile Griff.) é uma planta originária da Malásia de porte herbáceo, rizomatosa, perene que produz inflorescências terminais de forma cilíndrica em profusão. As brácteas são de coloração amarelo-brilhante a róseo-avermelhada, sustentadas por haste ereta que se origina diretamente do sistema de rizomas ficando completamente separadas das hastes vegetativas (LAMAS, 2002).

É uma planta ornamental com imensa diversidade de uso, podendo ser utilizada em maciços nos jardins, em áreas arborizadas, em bosques e sua beleza exótica tem lhe conferido destaque como flor de corte.

Segundo PETRY et al. (2000), as flores cortadas estão sujeitas a todos processos fisiológicos e patológicos, deteriorando-se de modo semelhante ao das frutas e hortaliças com suas reservas compostas principalmente por carboidratos, diminuindo gradativamente pela respiração.

O ponto de colheita é fator relevante na conservação pós-colheita de flores, podendo influenciar diretamente na qualidade do produto, para LAMAS (2003), a inflorescência de Zingiber spectabile deve ser colhida com o ponto variando conforme a exigência do mercado, ou seja, da fase de botão à inflorescência totalmente aberta.

A colheita sendo efetuada em ponto mais fechado pode oferecer vantagens para o produtor como maior flexibilidade de mercado, menos perdas decorrentes de condições ambientais, menor incidência de pragas e moléstias, flores menos suscetíveis a danos mecânicos durante a colheita, manuseio e transporte (ROCANCIO, 1992).

A manutenção da qualidade deve-se às técnicas de armazenamento pós-colheita que reduzem as taxas respiratórias, retardam a senescência e atuam na prevenção de desordens fisiológicas (SOUSA et al., 2002).

OLIVEIRA (1996) relata que a estocagem refrigerada é extremamente efetiva na redução da respiração e preservação dos suprimentos de reservas, e para AWAD (1993), a utilização de modificadores de atmosfera gasosa em produtos vegetais prolonga o tempo de armazenamento.

No armazenamento sob atmosfera modificada, as concentrações reduzidas de $\mathrm{O}_{2}$ e elevadas de $\mathrm{CO}_{2}$, no interior da embalagem, reduzem as taxas de respiração e de produção de etileno, tornando mais lenta as mudanças associadas ao amadurecimento e retardando a senescência dos produtos hortícolas.

O presente trabalho teve como objetivo avaliar a qualidade e conservação de hastes florais de Zingiber spectabile Griff. colhidas em dois estádios de desenvolvimento e revestimento ou não em filme plástico de cloreto de polivinila (PVC) durante o armazenamento.

\section{MATERIAL EMÉTODOS}

Hastes de sorvetão (Zingiber spectabile Griff.), cultivados em ambiente protegido por sombrite $70 \%$, foram colhidas no Câmpus Experimental da Embrapa Agroindústria Tropical, situada em Fortaleza -CE, no início da manhã.
Nesse trabalho, adotou-se o termo haste floral para o conjunto que compreende caule e inflorescência.

Procurou-se estabelecer dois estádios de colheita para as hastes florais: inflorescências com abertura completa na região apical chamado de estádio 1 e, inflorescências com abertura incompleta na região apical de estádio 2 (figura 1).

Após a colheita, o material foi conduzido para o Laboratório de Fisiologia e Tecnologia Pós-colheita onde as hastes foram submetidas ao processo de limpeza: remoção dos restos florais, lavagem em água e sabão neutro com auxílio de esponja macia para a retirada de impurezas oriundas do campo, imersão em solução com fungicida Mancozeb (20 g/L) por 30 segundos e em seguida imersas em água para retirar o excesso do produto.

Após o processo de limpeza, as hastes foram cortadas na base e acondicionadas por uma hora em recipientes com água proveniente de distribuidor público, para hidratação dos tecidos vegetais e a secagem das brácteas.

As hastes florais foram revestidas do ápice da inflorescência até a base do caule em filme plástico de cloreto de polivinila (PVC) $15 \mu \mathrm{m}$ e codificadas de acordo com o tratamento em:

IP - inflorescências com abertura incompleta com revestimento.

$\mathrm{CP}$ - inflorescências com abertura completa com revestimento.

IS - inflorescências com abertura incompleta sem revestimento.

CS - inflorescências com abertura completa sem revestimento.

$\mathrm{O}$ experimento foi conduzido em delineamento inteiramente casualizado em esquema fatorial $2 \times 2$, o primeiro fator referiu-se aos estádios de colheita e o segundo, ao uso ou não do filme de PVC; com três repetições e cinco hastes por repetição, totalizando 15 hastes por tratamento.

As hastes florais foram armazenadas em caixas de papelão ondulado, tipo telescópica (dimensões: $1 \mathrm{~m}$ de comprimento, $0,32 \mathrm{~m}$ de largura e $0,2 \mathrm{~m}$ de altura) usadas comercialmente (figura 2), sob refrigeração $15^{\circ} \mathrm{C}$ e UR $85 \%$. As avaliações foram diárias até o momento do descarte por acompanhamento de perda de massa fresca e sob critério de notas, adaptado de Castro (1993), definido para comparar e verificar a conservação dos aspectos visuais:

0 - Haste e/ou inflorescência túrgida e de coloração característica.

1 - Início de amarelecimento e/ou murcha da haste.

2-Amarelecimento e/ou murcha parcial da haste e/ou início de murcha das brácteas.

3 - Haste murcha e/ou amarela e murcha parcial das brácteas.

4 - Brácteas murchas e/ou quebra da base da inflorescência.

Os dados foram submetidos à análise de variância, realizadas com auxílio do programa computacional SISVAR versão 4.03. As médias entre tratamentos foram obtidas por meio do teste Tukey a 5\% de probabilidade.

Consideraram-se inflorescências com nota média igual ou inferior a dois com qualidade comercial e com nota média zero as com melhor potencial comercial. 


\section{RESULTADOS E DISCUSSÃO}

Segundo GONZAGA et al. (2001), o balanço hídrico é considerado fator determinante na longevidade dos órgãos das plantas, a deficiência de água nas plantas acelera a senescência e, conseqüentemente a vida de vaso da flor cortada.

Estudos realizados com atmosfera modificada por NEVES et al.(2004) e YAMASHITA et al. (2002) mostraram eficiência na manutenção da massa fresca em frutos e hortaliças.

O revestimento com filme PVC foi eficiente na manutenção da massa fresca das hastes florais, mas no momento do descarte houve perda percentual de $2,6 \%$ e $2,4 \%$ para hastes de inflorescências com abertura incompleta e abertura completa respectivamente. Hastes não-revestidas tiveram perda percentual de $10 \%$ para abertura completa e $11 \%$ para abertura incompleta (figura 3 ).

Embora o revestimento PVC tenha sido eficiente na manutenção da perda de massa fresca das hastes de sorvetão, os pontos de colheita adotados não diferiram entre si quando submetidos à mesma condição de atmosfera.

Durante o período de armazenamento (13 dias), os tratamentos diferiram significativamente $(p=0,05) \mathrm{em}$ relação às notas referentes à qualidade das hastes analisadas (figura 4).

O tratamento de inflorescências com abertura completa revestida obteve notas médias superiores às hastes não-revestidas com PVC durante todo o período do armazenamento, porém diferindo estatisticamente do tratamento de abertura completa revestidas com PVC somente a partir do $10^{\circ}$ dia após a colheita.

Houve interação entre ponto de colheita e embalagem, ou seja, no processo de armazenamento, o ponto de colheita associado à embalagem influenciou na manutenção da qualidade das hastes florais.

A qualidade comercial, parâmetro considerado quando as hastes florais têm características que conferem à comercialização do produto, foi conservada por 11 dias após a colheita em hastes colhidas com ponto fechado e revestidas por PVC.

Para o produtor, esse dado é de grande importância, visto que o mesmo poderá manter seu produto armazenado com potencial de comercialização durante 11 dias, após a colheita das hastes florais.

O momento do descarte do tratamento com inflorescência de abertura incompleta e revestida com PVC, as notas médias foram superiores a $3-$ após o $13^{\circ} \mathrm{dia}$ da colheita, - superior aos demais tratamentos, que foram descartados no $12^{\circ}$ dia.

Considerando que as hastes foram acondicionadas sem hidratação, o período em que as hastes permaneceram armazenadas foi bem significativo quando comparado com os resultados de ALMEIDA et al. (2001) que, testando o efeito de 1-metilciclopropeno na conservação de hastes de Zingiber spectabile armazenadas a $15^{\circ} \mathrm{C}$ sob hidratação, observou que as hastes florais tiveram média de 15 dias de vida de prateleira.

\section{CONCLUSÕES}

$\mathrm{O}$ revestimento das hastes com filme PVC mostrou-se eficiente na redução da perda de massa fresca para ambos os pontos de colheita.

As hastes armazenadas com ponto de colheita fechado e com revestimento plástico apresentaram melhor qualidade durante o período do armazenamento.

\section{REFERÊNCIAS}

ALMEIDA, A.S.; ALVES, R.E.; PAIVA, W.O.; LIMA, M.C.; ALMEIDA, J.B.S.A. Qualidade e conservação de sorvetões (Zingiber spectabilis) tratado em pós-colheita com 1metilciclopropeno (1-MCP). Interamerican Society Tropical Horticulture. v. 46, p. 110-111, 2002.

AWAD, M. Fisiologia pós-colheita de frutos. São Paulo, SP: Nobel, 1. ed., 1993.113p.

CASTRO, C.E.F. de. Helicônias como flores de corte: adequação de espécies e tecnologia pós-colheita. 1993. 191p. Tese de Doutorado (Fitotecnia). Universidade de São Paulo, Piracicaba, SP.

GONZAGA, A.R.; MOREIRA, L.A.; LONARDONI, F.; FARIA, R.T. Longevidade pós-colheita de inflorescências de girassol afetada por nitrato de prata e sacarose. Revista Brasileira de Horticultura Ornamental, Campinas, v.7, n.1,p.73-77, 2001.

LAMAS, A.M. Floricultura tropical: avanços tecnológicos. Fortaleza: Instituto Frutal, 2003. 98p.

LAMAS, A.M. Floricultura tropical: técnicas de cultivo. Recife, PE: SEBRAE, 2002. $84 \mathrm{p}$.

LOPES, S.L.; GRAZIANO, T.T. A produção e a comercialização de Heliconia spp. no estado de São Paulo.

Revista Brasileira de Horticultura Ornamental, Campinas, v.7, n.2, p.81-88, 2001.

NEVES, L.C.; BENDER, R.J.; ROMBALDI, C.V. Storage in passive modified atmosphere of 'Golden Star' starfruit (Averrhoa carambola L.). Revista Brasileira de Fruticultura, Apr. 2004, vol.26, n.1, p.8-12. ISSN 0100-2945.

OLIVEIRA, M.J.G de. Tecnologia pós-colheita de Heliconia spp. 1996. 111 p. Dissertação de Mestrado (Préprocessamento de produtos agrícolas). Universidade Estadual de Campinas, Campinas, SP.

PETRY, C.; CALVETE, E.O.; SILVA, L. da; REDAELLI, L.R.; HEINECK, M.A.; FERMINO, M.H.; GROLLI, P.R.; BELLÉ, S. Plantas ornamentais: aspectos para a produção. Universidade de Passo Fundo. Passo Fundo, RS: Editora Universitária, 2000. 155p.

ROCANCIO, V.J.F. Adequação do ponto de colheita e conservação pós-colheita de crisântemos (Chrysanthemum sp.). 1992.96 p. Dissertação de Mestrado (Produção Vegetal). Universidade Estadual Paulista, Jaboticabal, SP.

SOUSA, J. P. de; PRACA, E.F.; ALVES, R.E. Influência do armazenamento refrigerado em associação com atmosfera modificada por filmes plásticos na qualidade de mangas 'Tommy Atkins. Revista Brasileira de Fruticultura, Dez. 2002, vol. 24, no. 3, p.665-668. ISSN 0100-2945. 
YAMASHITA, F.; MIGLIORANZA, L.H. da S.; MIRANDA,

L. de A. et al. Effects of packaging and temperature on postharvest of atemoya. Revista Brasileira de Fruticultura, v..24,n..3, p.658-660, Dec. 2002.
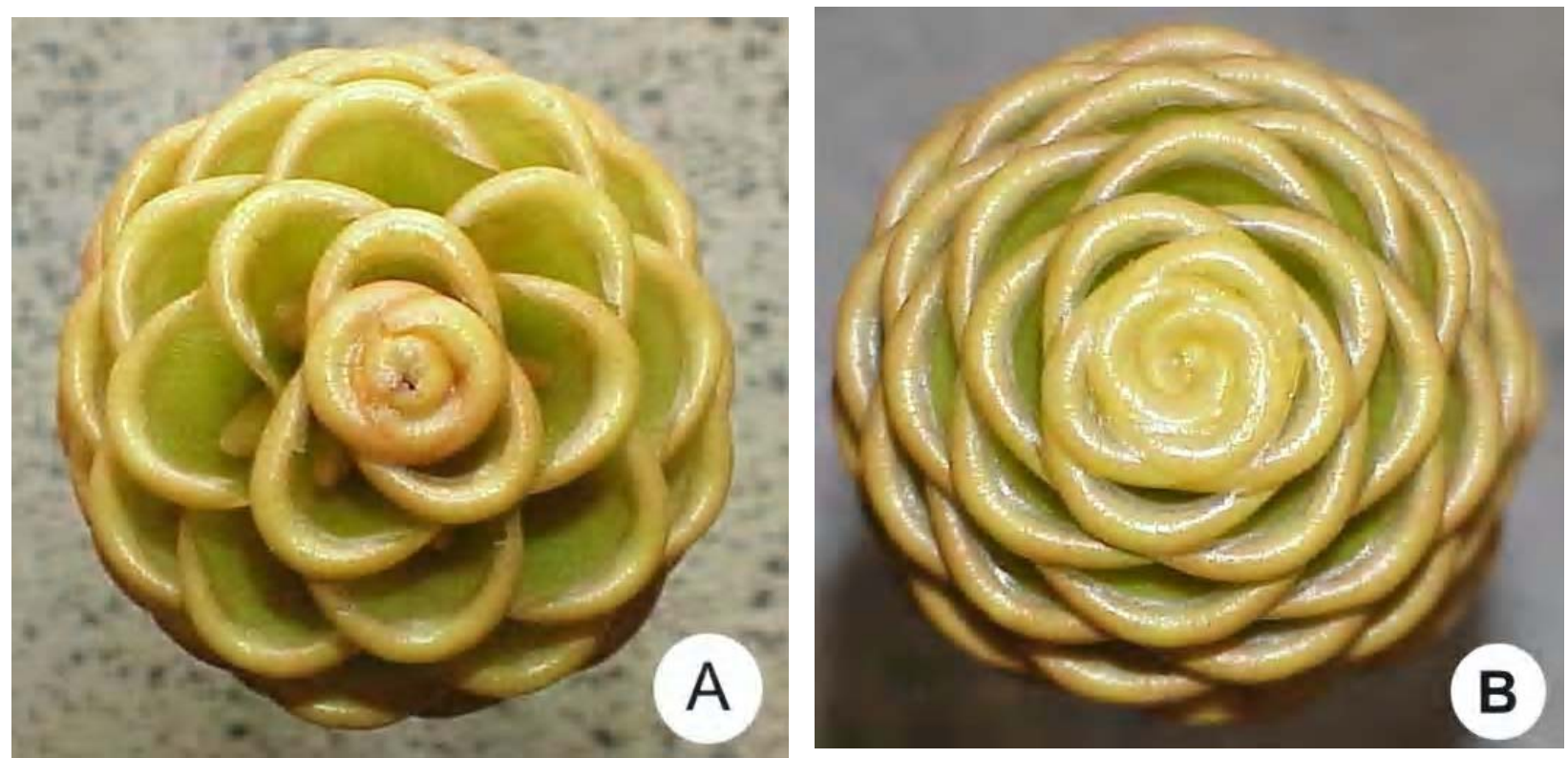

Figura 1. Pontos de abertura adotados no experimento, ponto com abertura completa na região apical (A) e inflorescências com abertura incompleta na região apical (B).
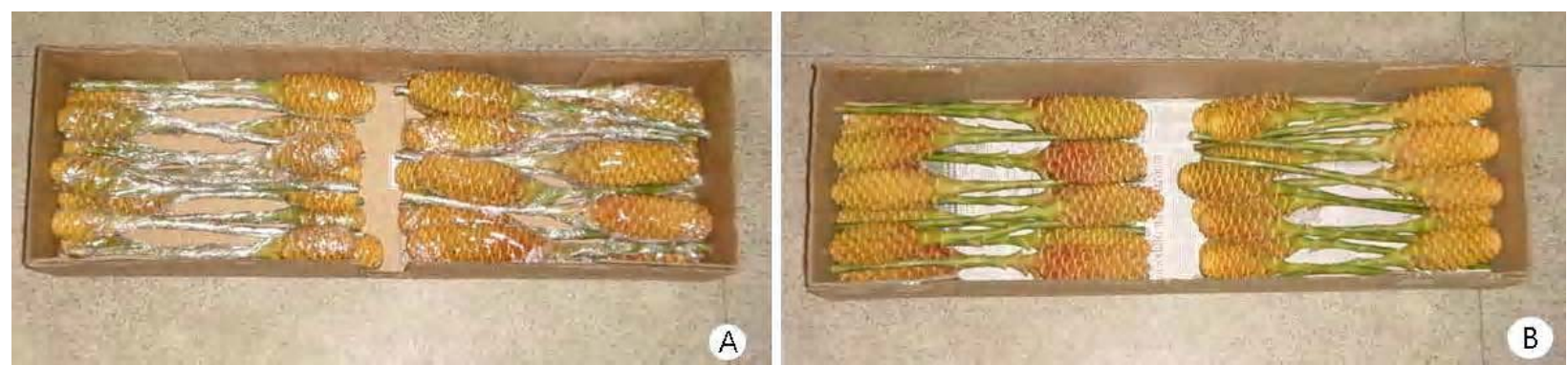

Figura 2. Armazenamento de hastes de sorvetão em caixas telescópicas em ambiente refrigerado $\left(15^{\circ} \mathrm{C}\right.$ e UR $85 \%$ ), adotando dois pontos de colheita e revestimento ( A) ou não em filme de PVC (B). 


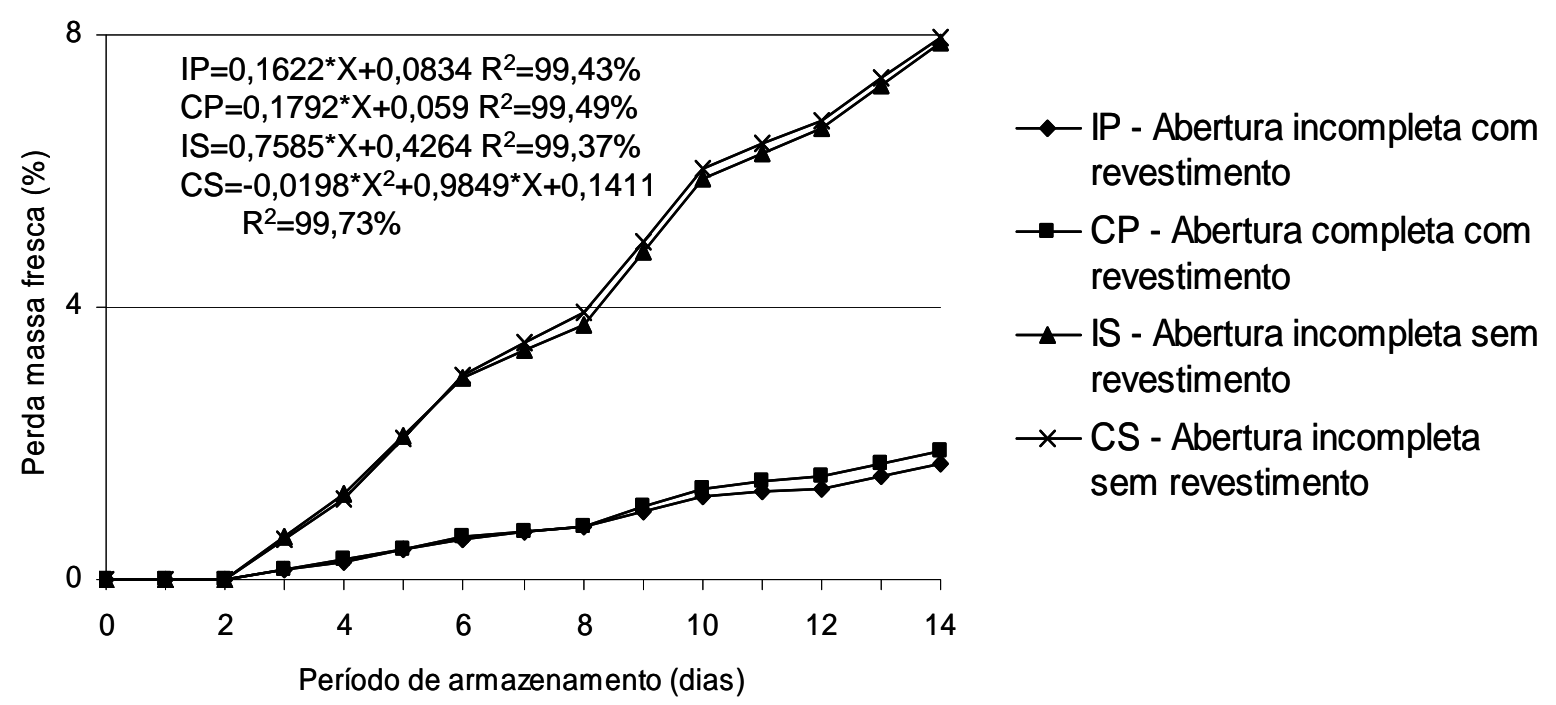

Figura 3. Variação acumulada na massa fresca de inflorescência de sorvetão, utilizando dois pontos de colheita e revestimento ou não em filme PVC.

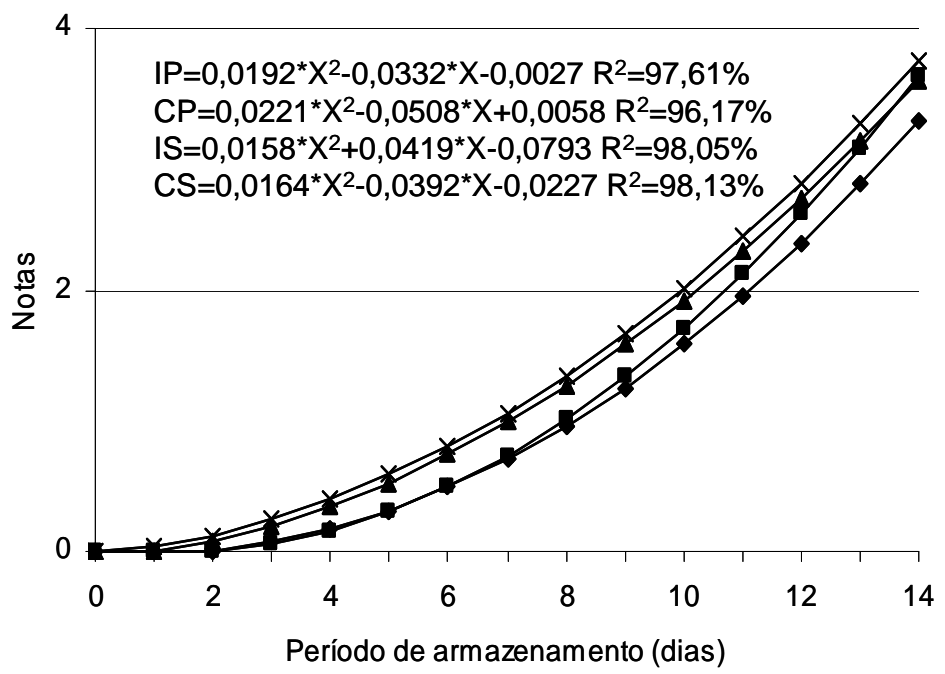

$\rightarrow-\mathbb{P}$ - Abertura incompleta com revestimento

$\rightarrow$ CP - Abertura completa com revestimento

$\rightarrow$ IS - Abertura incompleta sem revestimento

$\rightarrow$ CS - Abertura incompleta sem revestimento

Figura 4. Variação da qualidade visual de inflorescência de sorvetão, utilizando dois pontos de colheita e revestimento ou não em filme PVC. 